\title{
Miscellany
}

\section{Defeat Depression Campaign Fun Run}

To herald the Defeat Depression Action Day, a Fun Run was held on Sunday, 9 April 1995 in Battersea Park, London at which over 250 people ran, including psychiatrists, GPs, social workers, CPNs, nurses, users and more than half the staff from the College. Here we see Professor Robin Priest, Chairman of the Campaign, during the warm-up led by Kara Noble, former DJ from Capital Radio's breakfast programme.

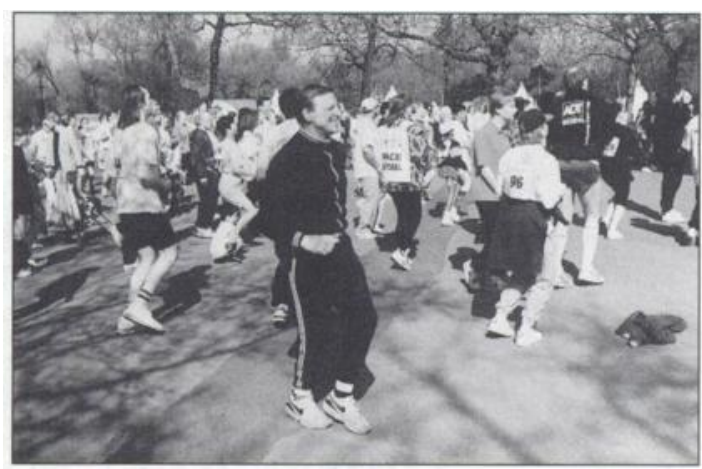

\section{Awards}

The Kurt Schneider Award, sponsored by Janssen GmbH and endowed with 10000 DM, will be awarded for the sixth time in 1996. The award aims to encourage psychiatric research, especially in the field of schizophrenia, including basic research (clinical psychopathology, biochemistry, physiology, pharmacology, genetics, epidemiology), diagnostics, therapy and rehabilitation. Further information: Professor Dr med. Dr h.c. Gerd Huber, Department of Nervous Diseases of the University, D-5300 Bonn 1 (Venusberg), Germany.

The Whitbread Volunteer Action Awards are now in their 13th year. They cover Scotland, Wales and England and each winner receives $£ 1000$, half of which must be donated towards their cause. A further $£ 1000$ is given to the Whitbred Volunteer of the Year - an overall winner chosen from 12 categories. Entries for this year's awards must be received by 22
September 1995. Nomination forms are available by writing to Whitbread Volunteer Action Awards, Freepost LOL 1936, Luton, Beds LU1 3YR (no stamp required), or by calling 01582397759.

\section{The Institute of Epileptology}

The Institute of Epileptology has been launched to establish the leading academic centre of excellence in Europe for the study of epilepsy; to promote basic, clinical and communty/general practice-based research in epilepsy; to promote teaching courses for medical and allied health professionals in the UK and Europe; and to raise the profile of epilepsy, a common but academically neglected disorder. A wide range of courses are being planned, including an MSc in Epileptology, which will be launched in October 1995. The Director is Dr Edward H. Reynolds and the Chairman Mr Evan D. R. Stone at The Institute for Epileptology. The Centre for Epilepsy, The Maudsley Hospital, Denmark Hill, London SE5 8AZ (telephone 0171277 1985).

\section{Campaign for Disabled People}

The Suzy Lamplugh Trust has launched a campaign to promote greater personal safety for disabled people. The campaign is the result of two years of investigation by a Home Office Working Party set up at the instigation of the Trust. In the first year of the campaign the Trust plans six workshops around the country. To receive the consultation paper Guidance on Personal Safety for Disabled People and pilot safety leaflet Out and About (the leaflet is available in print or on cassette), please send a self-addressed label and stamps to the value of $£ 1.50$ to The Suzy Lamplugh Trust, 14 East Sheen Avenue, London SW14 8AS. For a copy of Out and About only, send an A5 stamped addressed envelope marked O\&E. For a cassette also write ' $C$ ' on the envelope.

\section{New publications}

Mental Health in Learning Disabilities, edited by Nick Bouras, Bernadette Murray, Theresa 